\title{
Surface plasmon assisted electron-hole migration for high photocurrent density generation in perovskite solar cell
}

Mohamed Salleh Mohamed Saheed ${ }^{1}$, Norani Muti Mohamed ${ }^{1,2, *}$, Balbir Singh Mahinder

$$
\text { Singh }^{1,2} \text {, Rajan Jose }{ }^{3}
$$

${ }^{1}$ Department of Fundamental and Applied Sciences, Universiti Teknologi PETRONAS, 32610 Seri Iskandar, Perak, Malaysia.

${ }^{2}$ Centre of Innovative Nanostructures and Nanodevices (COINN), Universiti Teknologi PETRONAS, 32610 Seri Iskandar, Perak, Malaysia.

${ }^{3}$ Nanostructured Renewable Energy Materials Laboratory, Faculty of Industrial Sciences \& Technology, Universiti Malaysia Pahang, 26300 Kuantan, Malaysia.

*Corresponding author:

E-mail: noranimuti_mohamed@utp.edu.my

\section{Supporting Information}

\section{SI-Result and Discussion}




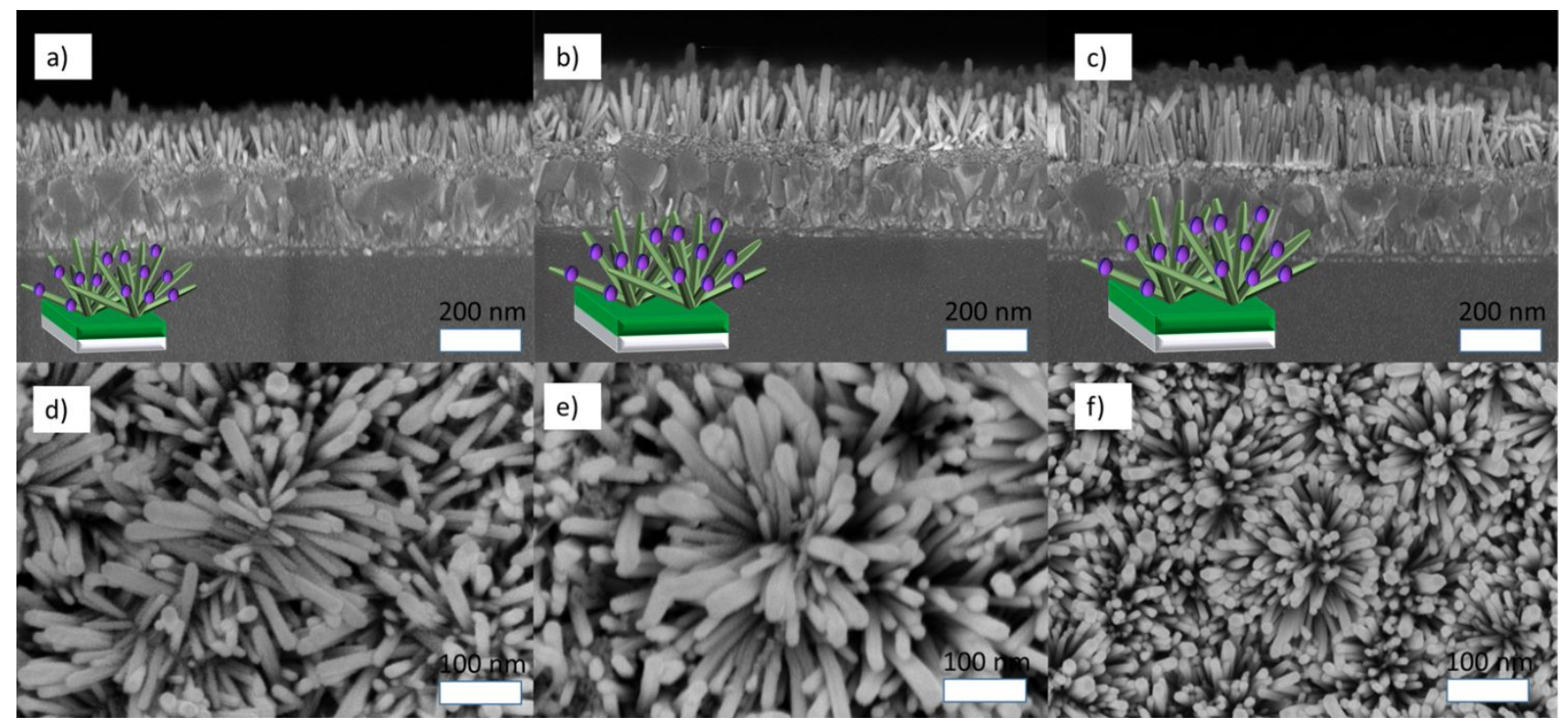

Figure S1: SEM cross sectional image of Au:ZnO NFs grown for a) $3 \mathrm{~h} \mathrm{~b}$ ) $4 \mathrm{~h}$ c) $5 \mathrm{~h}$ and their respective top view for d) $3 \mathrm{hrs} \mathrm{e)} 4 \mathrm{hrs} \mathrm{f)} 5 \mathrm{hrs}$.

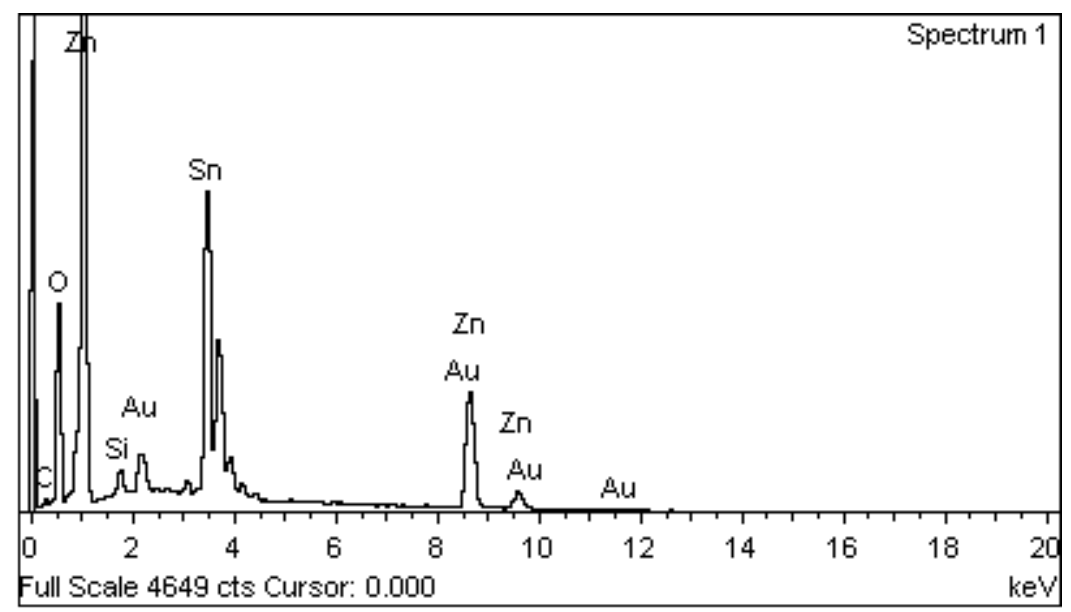

Figure S2: EDX spectrum of $\mathrm{Au}: \mathrm{ZnO} \mathrm{NFs}$.

The asymmetric O1s scan spectrum depicted in Figure 1d(ii), can be de-convoluted into three peaks where the binding energies are given to be $530 \mathrm{eV}, 531.4 \mathrm{eV}$ and $532.5 \mathrm{eV}$ which indicates the $\mathrm{O}^{2-}$ in lattice $(\mathrm{OL}), \mathrm{O}$ defects $(\mathrm{OD})$ and $\mathrm{O}$ chemisorbed $(\mathrm{OC})$, respectively. High ratio between the OD and OC shows the amount of surface defects (hydroxyl group) present which 
results in better photo-induced electrons. The corresponding binding energies of Au4f can be observed at $83.6 \mathrm{eV}$ and $87.8 \mathrm{eV}$ as in Figure $1 \mathrm{~d}(\mathrm{i})$.
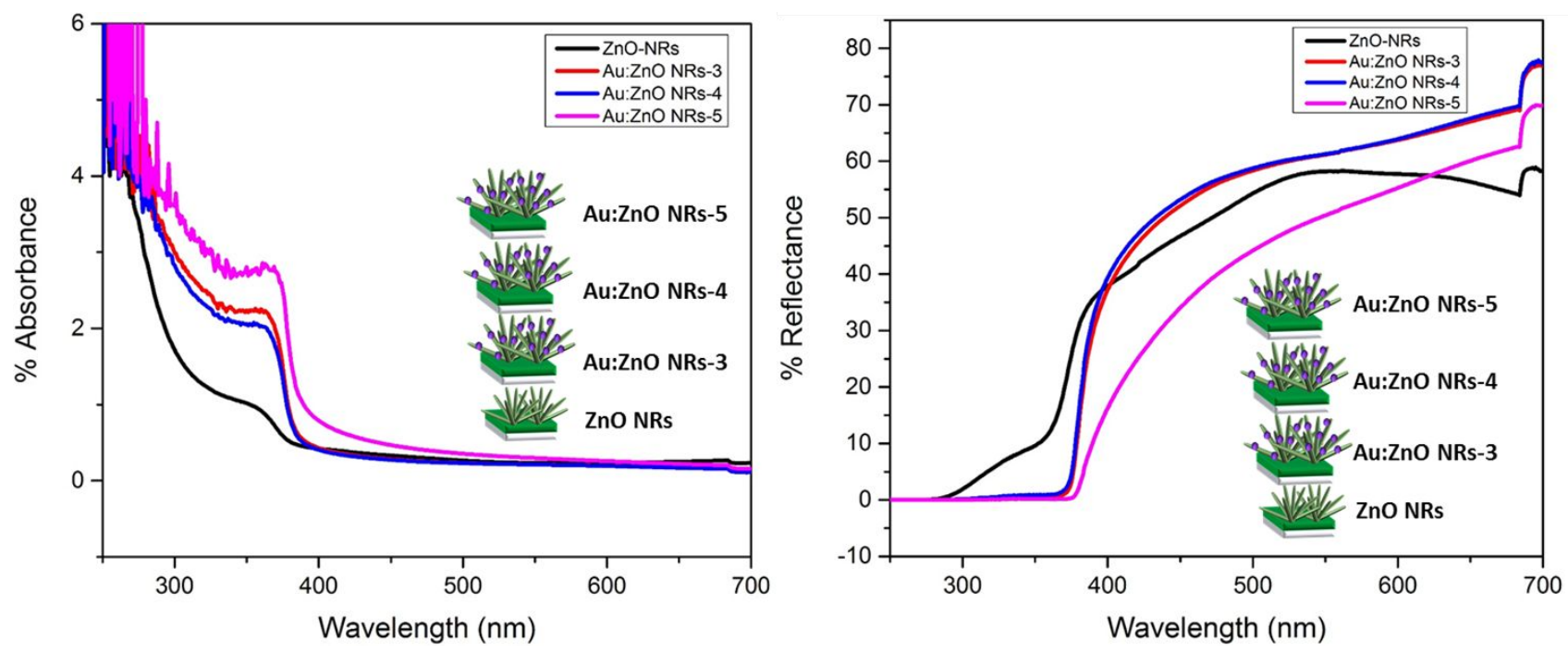

Figure S3: UV-visible spectrum of ZnO-NFs and $\mathrm{Au} Z \mathrm{ZnO}$ NFs $(3,4,5)$ showing the a) absorbance and the b) reflectance.

The UV-visible spectrum of reflectance and absorbance were obtained for the pristine ZnO-NFs and Au:ZnO NFs (sample 3,4, and 5) as depicted in Figure S3. The visible light reflectance curves for the range of 380 to $700 \mathrm{~nm}$ are observed for the as grown and hybrid samples in Figure $\mathrm{S} 4 \mathrm{~b}$. The pristine $\mathrm{ZnO}-\mathrm{NFs}$ exhibits the reflectance of maximum 55\% in the visible range while the Au:ZnO NFs-3 and Au:ZnO NFs-4 show some differences where almost 68\% reflectance is observed for $\mathrm{Au}: \mathrm{ZnO} N F s-4$ and $64 \%$ for $\mathrm{Au}: \mathrm{ZnO} \mathrm{NFs}-3$. Meanwhile the $\mathrm{Au}: \mathrm{ZnO}$ NFs-5 exhibits 50\% reflectance compared to other nanostructures. Generally, a stable reflectance plateau is observed for all Au devices. The absorbance of the ZnO-NFs and Au:ZnO NFs $(3,4,5)$ are also plotted as in Figure S4a. Due to the nature of wurtzite hexagonal $\mathrm{ZnO}$, strong band edge absorbance is observed at $373 \mathrm{~nm}^{1}$. As the length of nanorods increases, the absorbance increases, typically from $0.75 \%$ to $2 \%$ at $373 \mathrm{~nm}$. 


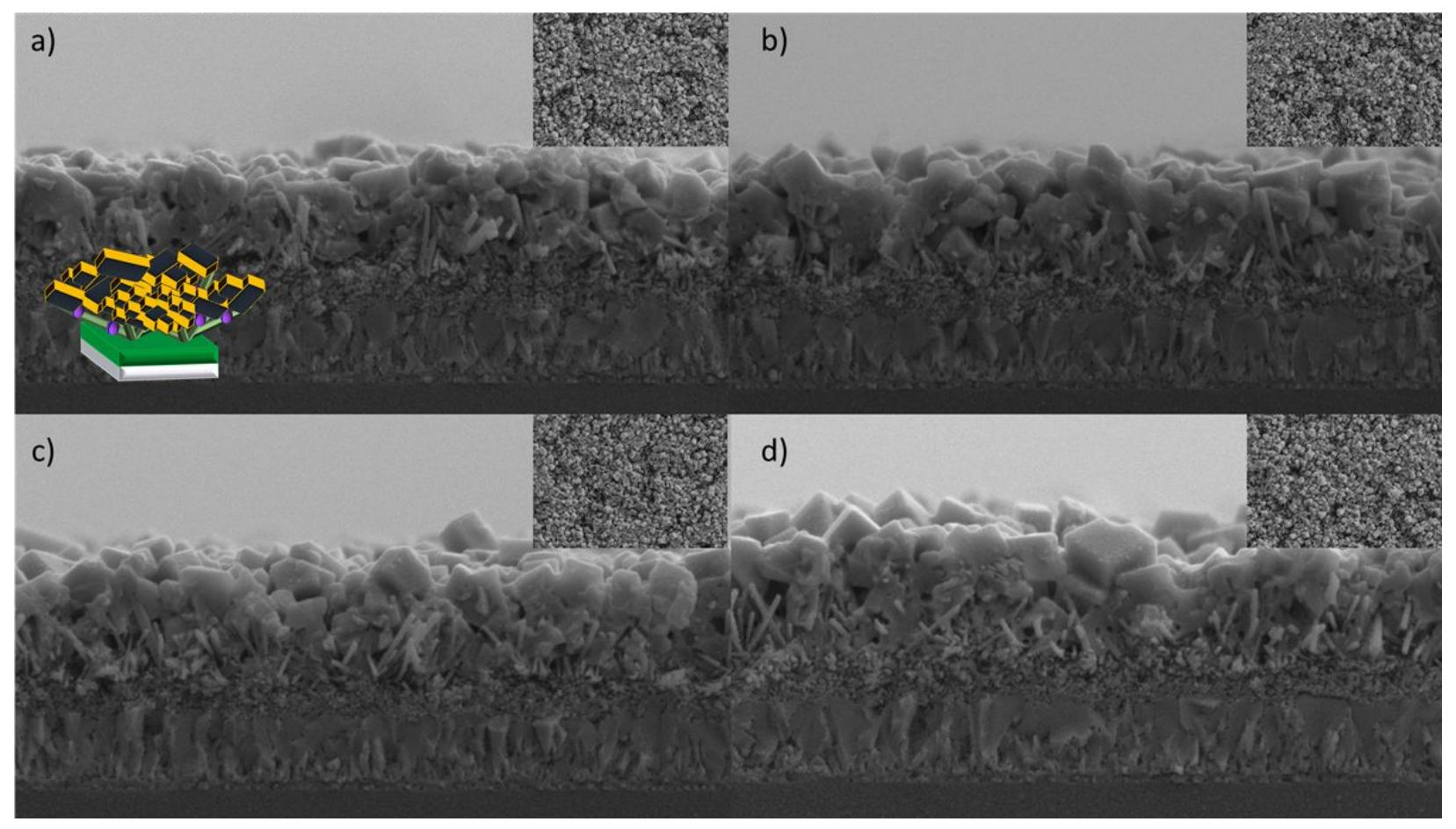

Figure S4: SEM cross sectional image of $\mathrm{CH}_{3} \mathrm{NH}_{3} \mathrm{PbI}_{3}$ deposited on a) $\mathrm{ZnO}-\mathrm{NFs}$ b) 3 hrs c) 4 hrs d) 5 hrs with the inset for the surface morphologies.
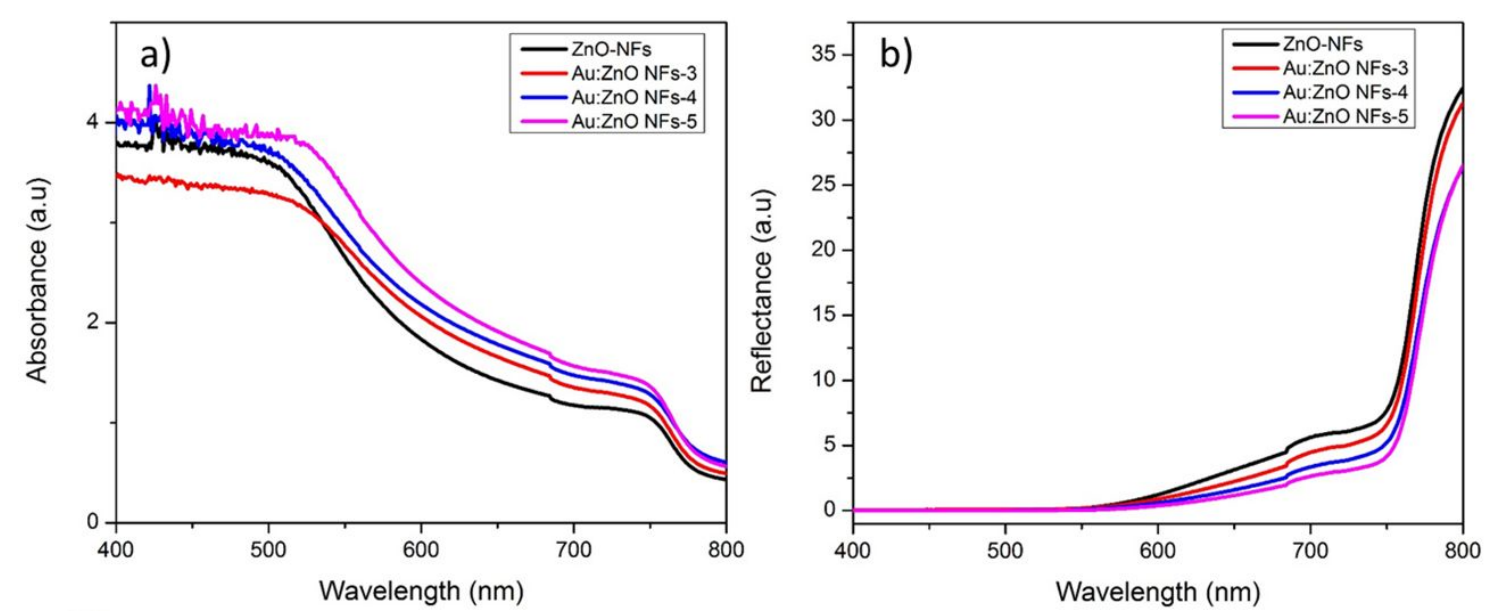

Figure S5: a) Absorbance b) reflectance of the $\mathrm{ZnO}-\mathrm{NFs}$ and $\mathrm{Au}: \mathrm{ZnO} \mathrm{NFs}(3,4,5)$ coated with $\mathrm{CH}_{3} \mathrm{NH}_{3} \mathrm{PbI}_{3}$.

Table S1: PSCs parameters current density $\left(J_{\mathrm{SC}}\right)$, open voltage $\left(V_{\mathrm{OC}}\right)$, fill factor $(\mathrm{FF})$ and power conversion efficiency (PCE) for all solar cells. 


\begin{tabular}{|l|l|l|l|l|}
\hline & $J_{\mathrm{SC}}\left(\mathrm{mA} / \mathrm{cm}^{2}\right)$ & $V_{\mathrm{OC}}(\mathrm{V})$ & FF & PCE (\%) \\
\hline ZnO-NFs (control) & $15.08 \pm 0.2$ & $0.49 \pm 0.02$ & $0.33 \pm 0.04$ & $2.41 \pm 0.40$ \\
\hline Au:ZnO NFs-3 & $18.71 \pm 0.6$ & $0.58 \pm 0.02$ & $0.40 \pm 0.03$ & $4.43 \pm 0.32$ \\
\hline Au:ZnO NFs-4 & $18.58 \pm 0.4$ & $0.52 \pm 0.03$ & $0.30 \pm 0.03$ & $2.29 \pm 0.24$ \\
\hline Au:ZnO NFs-5 & $17.38 \pm 0.5$ & $0.45 \pm 0.02$ & $0.44 \pm 0.08$ & $3.45 \pm 0.65$ \\
\hline
\end{tabular}

Table S2: Fitted parameters for EIS curves for all devices.

\begin{tabular}{|l|l|l|l|l|l|l|}
\hline & $\mathrm{R}_{\mathrm{S}}(\Omega)$ & $\mathrm{R}_{\mathrm{CT} 1}$ & $\mathrm{R}_{\mathrm{CT} 2}(\Omega)$ & $\mathrm{CPE}_{1}(\mu \mathrm{F})$ & $\mathrm{CPE}_{2}(\mu \mathrm{F})$ & $\mathrm{n}$ \\
\hline ZnO-NFs & 1.25 & 609.38 & 67.381 & 110.74 & 1.4217 & 0.94 \\
\hline control) & & & & & & \\
\hline Au:ZnO NFs-3 & 1.25 & 914.67 & - & 31.31 & - & 0.87 \\
\hline Au:ZnO NFs-4 & 1.48 & 848.58 & - & 106.68 & - & 0.81 \\
\hline
\end{tabular}

\section{Reference:}

(1) Zhang, X.; Qin, J.; Xue, Y.; Yu, P.; Zhang, B.; Wang, L.; Liu, R. Effect of Aspect Ratio and Surface Defects on the Photocatalytic Activity of ZnO Nanorods. Sci. Rep. 2015, 4 (1), 4596. https://doi.org/10.1038/srep04596. 